\title{
IMPACTO DA INICIATIVA EXTENSIONISTA NA COMUNIDADE LOCAL E NA FORMAÇÃO DO ESTUDANTE DO CURSO TÉCNICO EM MASSOTERAPIA: PROJETO "MÃOS ITINERANTES - MASSOTERAPIA EM EVENTOS"
}

\author{
Lívia Pimenta Renó Gasparotto; Claudia Monteiro dos Santos Bontorin; \\ Thalita Alves; Jorge Augusto Foss \\ livia.gasparotto@ifpr.edu.br; claudia.bontorin@ifpr.edu.br; thalitaalves04@hotmail.com; \\ foss.jorge@gmail.com \\ Instituto Federal de Educação, Ciência e Tecnologia do Paraná \\ DOI: 10.15628/rbept.2018.7025 \\ Artigo submetido em jan/2018 e aceito em fev/2018
}

\section{RESUMO}

Cada vez mais nota-se a vinculação de projetos de extensão para além de uma prática profissional. A extensão pode agregar propostas mais complexas como alinhar-se à filosofia do curso, atingir número expressivo da comunidade a que pertence sem deixar de lado o incentivo à pesquisa. Assim, a indissociabilidade entre ensino, pesquisa e extensão mostra-se viável e reforça o compromisso de um aprendizado qualificado. Além disso, o impacto na comunidade local sinaliza a importância dessa iniciativa nas instituições, principalmente no que diz respeito às escolas técnicas uma vez que valoriza a capacitação profissional sem desvincular o aluno do cenário em que vive sua comunidade. 0 artigo propõe uma reflexão sobre esse contexto de envolvimento do projeto de extensão alinhado às demais valências de uma escola técnica trazendo os dados de um projeto na área da saúde e ligado a uma escola de formação profissional técnica. Os números expressivos ligados ao seu impacto na comunidade bem como o contato direto com sua comunidade fortalece os espaços de aprendizagem e reforça a ideia de que é possível conciliar os instrumentos de aprendizado ligados ao ensino, pesquisa e extensão. Assim, o projeto "mãos itinerantes", premiado como melhor prática extensionista num universo de mais de 23 instituições técnicas do estado do Paraná em 2016, será aqui apresentado e também oferecido como objeto de reflexão para a importância da extensão no fortalecimento educacional e na transformação de uma realidade local.

Palavras-chave: extensão, saúde, aprendizado, sociedade, escolas técnicas. 


\section{ABSTRACT}

Extension projects as a professional practice in a technological schools have been encouraged in the next years. Extension can add more complex proposals such as aligning itself with the philosophy of the course, achieving an expressive number of the community to which it belongs without leaving aside the incentive to research. Thus, the indissociability between teaching, research and extension is feasible and reinforces the commitment of a qualified learning. In addition, the impact on the local community signals the importance of this initiative in the institutions, especially with regard to technical schools since it values the professional qualification without detaching the student from the scenario in which his community lives. The article proposes a reflection about this context of involvement of the project of extension aligned to the other valences of a technical school bringing the data of a project in the area of health and linked to a school of technical professional training. Expressive numbers linked to its impact on the community as well as direct contact with its community strengthens the learning spaces and reinforces the idea that it is possible to reconcile the learning instruments related to teaching, research and extension. Thus, the "traveling hands" project, awarded as best practice extensionist in a universe of more than 23 technical institutions in the state of Paraná in the last year, will be presented here and also offered as an object of reflection for the importance of extension in educational strengthening and transformation of a local reality.

KEYWORDS: extension, health, learning, society, technical schools 


\section{INTRODUÇÃO}

Já dizia Freire (1983) que a extensão é uma estratégia de construção de conhecimento conjunto, utilizando saberes do agente responsável (professor, mediador) junto com a comunidade externa. É um conhecimento co-produzido pois é transformado pela própria experiência de trabalho coletivo.

As práticas extensionistas têm sido discutidas cada vez mais nos últimos anos. A crescente movimentação literária no âmbito das práticas e versando a indissociabilidade da extensão com a pesquisa e o ensino (evidenciadas nas diretrizes das universidades e escolas técnicas) mostram-se cada vez mais presentes. A discussão teórica, então, sinaliza um movimento nas instituições que atuam nesse tripé ensino, pesquisa e extensão. Observa-se, também, aumento visível nos últimos anos da valorização da extensão através da criação de periódicos de extensão, congressos afins e maior financiamento governamental nessa proposta. Desse modo, um desafio para a extensão é realizar projetos de longo alcance social e educacional sem ferir, entre outros aspectos, o principio da educação gratuita nem enveredar para uma ótica mercantilista. (SILVA e VASCONCELOS, 2006)

Os benefícios que um projeto de extensão oferece são diversos e muito divulgados nos periódicos afins. Seixas et al. (2008) revelam que a atividade de extensão permite ao individuo a participação ativa através da oferta à comunidade de conhecimentos e de assistência tendo como principais retornos a obtenção de valores, da cultura local além da vivência e aperfeiçoamento profissional do estudante. Segundo os autores, projetos de extensão fornecem subsídios para que o profissional não se restrinja tão somente aos aspectos técnicos mas promove o olhar reflexivo sobre o contexto profissional e permite sua interação, intervenção e transformação do espaço.

A formação profissional aliada à experiência em projetos de extensão proporciona estímulos cognitivos, afetivos, psicomotores e também de cidadania. Essas competências permitem, entre outros aspectos, a maior compreensão sobre questões éticas e desafios profissionais diante da aproximação com a sociedade. Assim, atividades como monitoria de disciplina, iniciação científica e projeto de extensão são ferramentas determinantes na formação do aluno. (SEIXAS et al. 2008)

A inserção da extensão no meio institucional requer algumas estratégias para que se torne efetiva. Necessita da flexibilidade da estrutura curricular a fim de que esta viabilize a participação do aluno em atividades de extensão creditadas como componente curricular. Reforça-se, ainda, que maior ousadia seria se fosse proposto um modelo de extensão inserida na formação continuada, do primeiro semestre ao último. (PIERSON et al. 2005)

Conforme Souza, Torres e Dantas (2017) a prática (do termo "práxis") e a teoria podem ser agrupadas sob uma ótica de unidade em que prática é o resultado da teoria, ou seja, a prática não é criada uma vez que a inovação se dá pela teoria. É uma união recíproca. É necessário, portanto, que o professor da educação profissional seja capaz de criar situações de 
aprendizagem nas quais o jovem desenvolva capacidades como enfrentar as situações da prática social e do trabalho. Esse docente que se apropria do conhecimento prático e teórico vence as dificuldades e vê com clareza as novas possibilidades de reflexão e crítica dessas práticas.

O professor da educação profissional deve oferecer através da oferta da prática profissional o referencial sobre o quê, para quê e quem estão envolvidos na finalidade do ensino-aprendizagem. Também é importante que esse professor tenha um completo conjunto de conhecimentos que permitam trabalhar e dialogar com diferentes campos de formação. Em resumo, trata-se de um modo de operar que vai além do conteúdo teórico da disciplina. Assim, a atuação em práticas extensionistas torna-se uma estratégia para traspor os conteúdos específicos para uma realidade mais complexa. (SOUZA, TORRES E DANTAS, 2017)

\section{FORMAÇÃO TÉCNICA NA ÁREA DA SAÚDE: A EXTENSÃO COMO PRÁTICA INDISSOCIÁVEL DA PESQUISA E ENSINO}

A educação profissional foi regulamentada pela Lei 9394/96 de Diretrizes de Bases (LDB) e desde então nota-se expressivo crescimento da área da saúde no âmbito do ensino técnico. Docentes que atuam nessa área devem estar atentos de que o aprendizado quando vinculado à vivência desse futuro profissional o torna mais capaz de enfrentar os desafios da formação. No entanto, considerando a diversidade de cursos ofertados os projetos de extensão vinculados a tais cursos são ainda pouco visíveis à comunidade acadêmica dada a escassez de relatos nos periódicos afins.

Silva e Vasconcelos (2006) ao analisarem suas ações desenvolvidas no projeto de extensão identificaram escassa percepção dos professores de que a extensão é capaz de agregar-se à pesquisa e ao ensino. Apesar disso os autores observam que há um aumento na quantidade e diversificação das ações, sinalizando sutil valorização da extensão. Assim, nota-se que a formação do aluno vai além da aquisição de conhecimento técnico científico e que estes esvaziam-se quando não integrados à realidade.

Corroborando o exposto acima o trabalho de Souza, Torres e Dantas (2017) evidenciou numa análise qualitativa dos estudantes de saúde participantes de um projeto de extensão que a maioria dos entrevistados acreditam que a relação teoria e prática são essenciais e que a prática depende da teoria, assim como a teoria depende da prática. Outro projeto conduzido por Pezzani et al. (2017) permitiu que o espaço educacional fosse reconhecido como parte da comunidade. A comunidade é vista como um espaço onde se aprende, se investiga, se constrói alianças institucionais. Eles compreenderam que quando os alunos encontram mais sentido à sua aprendizagem, se motivam. Tais experiências impactam consistentemente na compreensão e aplicação de conhecimentos, no pensamento reflexivo e crítico.

Nota-se, então, que na área da saúde é importante trabalhar com metodologias que privilegiem aquisição de competência. A participação de estudantes na comunidade promove 
oportunidades para discussões baseadas na resolução de problemas reais. Trabalhar em ambientes complexos em que se põe à prova os conhecimentos acadêmicos, inter-disciplinar e a interação com diferentes atores da sociedade promove uma formação qualificada. (PEZZANI et al. 2017)

Autores como Lanzieri et al. (2011) relatam que há uma fragmentação do processo de trabalho e das relações entre os diferentes profissionais assim com uma precária interação entre equipes e despreparo para lidar com a dimensão subjetiva nas práticas de atenção. A humanização da saúde é discutida segundo aspectos como valorização dos diferentes sujeitos implicados no processo de produção da saúde, ênfase na autonomia, corresponsabilidade, vínculos solidários e participação coletiva nos cuidados em saúde. Através da vivencia relatada pelos alunos desses autores em seu projeto de extensão identificou-se que a experiência vivida possibilitou atuar sobre a dificuldade em lidar com afetividade, estabelecimento de vínculos, interações.

Nesse cenário das práticas em saúde, observam-se as terapias alternativas e complementares que vêm sendo demandada na saúde pública por meio de uma política de saúde chamada Política Nacional de Práticas Integrativas e Complementares (PNPIC). 0 documento prevê que práticas corporais devem buscar a inclusão da comunidade como um todo, pois seus benefícios refletem principalmente a prevenção de doenças e promoção da saúde. Entretanto, na prática ainda se observa pouca divulgação além da dificuldade de alocar esses profissionais no setor da atenção básica.

Sob a ótica dessa política pública de saúde há uma necessidade de mais profissionais promotores do holismo, isto é, que integram práticas na amplitude corpo, mente, espírito. Tal prática aproxima a relação entre profissional e indivíduo e essa permite, além dos benefícios físicos, o compartilhamento de saberes e de condutas saudáveis. Permite, além disso, o reconhecimento do indivíduo sobre suas necessidades em saúde, consciência preventiva em função de um viver com menores índices de doenças. (ESTACIO et al. 2015)

Para os participantes do projeto conduzido pelos autores acima, os principais destaques referentes a essa participação foram a obtenção de maior segurança diante das atitudes a serem tomadas e a troca de experiência. Segundo os autores, esta vivencia promove o desenvolvimento da formação profissional através da gestão da maturidade, autonomia. Além disso, foi relatado que o percorrer do projeto exigiu habilidades como flexibilidade, criatividade, trabalho em grupo, capacidade de expressão, noções de empreendedorismo, respeito às diferenças e intimidade com suas tecnologias. (ESTACIO et al. 2015)

Por fim, parece que a necessidade do vinculo dos projetos de extensão com a prática profissional não é só demanda de curso técnico, mas também de universidades, demonstrando com isso a sobreposição ainda presente de um ensino dissociado dessas ferramentas. Percebese, por exemplo, no artigo de Resende et al. (2013) que há uma deficiência em relação ao acesso de estudantes de medicina às atividades de iniciação cientifica e extensão exigindo, portanto, maior sensibilização. Chizani et al. (2017) lembra, ainda, que o artigo 207 da constituição de 
88 prevê que as universidades $\{\ldots\}$ obedecerão ao princípio da indissociabilidade entre ensino, pesquisa e extensão.

Diante do exposto, nota-se a importância de cursos técnicos de saúde aproximarem o aluno do sentido sob o cuidar através do reconhecimento do contexto externo e da sua influência. Observa-se, também, que a experiência é cada vez mais rara pelo excesso de informações, de opinião, pela falta de tempo e o excesso de trabalho. As práticas extensionistas contribuem, portanto, para formar profissionais mais sensíveis e hábeis para lidarem com a complexidade de ser humano e da saúde humana.

Este trabalho tem por objetivo apresentar e discutir os impactos referentes às práticas do projeto de extensão intitulado "Mãos Itinerantes" no que diz respeito à comunidade local e à formação dos estudantes do curso técnico em Massoterapia do IFPR/Campus Curitiba. Além disso, diante da logística formada com a equipe do curso, nota-se que a prática também contribui na elaboração e execução dos projetos de pesquisa, reforçando ainda mais que é possível essa integração.

\section{METODOLOGIA}

A pesquisa foi estruturada a partir de dados catalogados no projeto de extensão intitulado "Mãos Itinerantes - Massoterapia em Eventos" vinculado ao curso Técnico em Massoterapia do Instituto Federal do Paraná - Campus Curitiba, no período entre 2012 a 2017. Os dados aqui apresentados retratam os seguintes aspectos: apresentação do projeto e dados relativos às suas resultantes como o envolvimento de discentes e práticas realizadas, envolvimento da comunidade externa através do número de instituições participantes e contribuições para a pesquisa, todos conforme o período analisado. Os resultados serão apresentados na sequência.

\section{0 projeto Mãos Itinerantes: apresentação}

O Curso Técnico em Massoterapia do Instituo Federal do Paraná - Campus Curitiba compreende uma formação de dois anos com conteúdos teóricos e práticos na área de práticas manuais. É constantemente solicitado a prestar serviços em eventos institucionais, educacionais, governamentais, sociais e filantrópicos na finalidade da aplicação das técnicas massoterápicas ensinadas durante a formação e assim propiciar um bem estar à comunidade assistida. Tal demanda passou a existir após a construção do projeto "Mãos Itinerantes" e dessa intenção de levar o conhecimento para além das salas de aula, atingindo diretamente a comunidade local.

A participação em eventos pelos alunos do Curso Técnico em Massoterapia do IFPR já acontece desde o início do curso ainda na Escola Técnica vinculada a Universidade Federal do Paraná sempre com o objetivo de privilegiar a integralidade da atenção à saúde, considerando as dimensões biológicas, psicológicas e sociais do processo saúde-doença, na medida em que preparam profissionais para atuar, ampliar e integrar ações de promoção, proteção da saúde e qualidade de vida. 0 projeto continuou a acontecer no início do Instituto Federal do Paraná (em 
2008) mas em 2012 ganhou a forma de um projeto de extensão.

Neste sentido, levar o aluno para atender diversas comunidades permite que os mesmos tenham as condições necessárias para desenvolverem as competências gerais da área profissional de saúde e as específicas desta habilitação. Assim, ele treinam as técnicas aprendidas durante o curso e observam o processo de trabalho do Técnico em Massoterapia respeitando os valores políticos e éticos, as condições de cada evento, mantendo o compromisso com a sociedade através da qualidade, do trabalho, da ciência, da tecnologia e das práticas sociais relacionadas com os princípios da cidadania responsável e humana.

A comunidade assistida recebe um momento de integração, descontração, percepção e descoberta de quanto a saúde é importante no dia a dia do ser humano e o quanto ela tem que ser priorizada no constante da prevenção de desordens físicas e doenças. 0 estresse está presente no cotidiano do homem e, portanto, esses momentos diferenciados que a massagem pode propiciar traz um bem estar que a muito não é vivenciado por esse homem tão comprometido nessa rotina de vida.

Para contribuir com a formação dos profissionais que desenvolvem essas práticas, e para que atuem em consonância com os paradigmas que orientam a oferta dos serviços de saúde, o Instituto Federal do Paraná através do Curso Técnico em Massoterapia prepara os profissionais mediante o desenvolvimento de suas atividades no exercício das técnicas massoterápicas em eventos institucionais, educacionais, governamentais, sociais e filantrópicos para que possam influir positivamente na saúde e no bem-estar dos indivíduos atendidos. Assim, o título do projeto já define seu objeto de ação em que "mãos" apontam o instrumento de trabalho e "itinerante" a sua característica principal que é levar a prática para espaços diferentes daqueles vividos no âmbito institucional.

Conforme cada solicitação de evento a coordenação do projeto Mãos Itinerantes Massoterapia em Eventos decide pela técnica massoterapêutica que será aplicada com base no local, na disponibilidade de espaço, no número de alunos e no objetivo da ação propriamente dita. Após a solicitação, organiza-se as informações transmitidas pelo solicitante, divulga-se a ação entre os docentes e alunos, seleciona-se professor(es) responsável(is) e finalmente número de alunos envolvidos. 0 transporte de alunos e equipamentos (cadeiras de massagem e macas) é definido em conjunto com quem solicitou o evento. Em troca, solicita-se que a instituição participante ofereça refeições aos alunos quando a atividade dura o dia inteiro ou lanche para atividades de meio período. Caso o solicitante não consiga arcar com o transporte, este é solicitado ao IFPR.

\section{RESULTADOS E DISCUSSÃO}

Ainda que o projeto tenha iniciado em 2008 de modo não formalizado e com base nas demandas do curso, foi em 2012 que se começou a tabular o quantitativo de alunos, de participantes e de quantos eventos tiveram a presença desse projeto. Com base nos últimos 
cinco anos (2012 a 2017) foi identificado os seguintes números: 6.199 atendimentos sendo, portanto, uma média aproximada de 1.240 para cada ano, totalizando 125 eventos.

0 projeto mãos itinerantes atende todo o tipo de público. Além de adultos, idosos e esportistas, há também crianças e adolescentes. A definição do perfil se dá pelos espaços de atendimentos que são instituições públicas, empresas, escolas particulares e públicas, ONGs, clubes, festas municipais e estaduais e eventos da terceira idade.

Participaram das práticas massoterapêuticas oferecidas nesse projeto um total de 1641 alunos entre os 125 eventos que aconteceram nesse período de cinco anos, tendo a média de 13 alunos por evento. A dinâmica exige que o aluno realize uma avaliação previa em que identifica dados de saúde de todos os participantes. Esse instrumento foi aproveitado para levantar o perfil de saúde das pessoas envolvidas nesses atendimentos. Foi possível identificar, portanto, o perfil das queixas relatadas nessa avaliação. Identificaram-se principalmente desconfortos relacionados às desordens musculoesqueléticas da coluna (região cervical e lombar) e região de ombros. Esse direcionamento para além da prática (em que ele busca dados de saúde do público e elabora o tipo de prática com base nessas informações) contribui para a reflexão dos conteúdos teóricos aprendidos em sala, num momento de atuação prática.

As ações previstas no projeto Mãos Itinerantes - Massoterapia em Eventos corroboram com ações de políticas públicas, como por exemplo, a inserção da medicina alternativa na rede pública de saúde. Apesar dos eventos raramente acontecerem em uma unidade de saúde, a Organização Mundial de Saúde (OMS) estimula o uso dessas práticas, de forma integrada à medicina alopática, preconizando o desenvolvimento de políticas que obedeçam a requisitos de segurança, eficácia, qualidade, uso racional e acesso (SANTANA e NASCIMENTO, 2016)

Pierson et al. (2005) enfatizam a importância do projeto de extensão estar vinculado ao curso e que o mesmo proponha flexibilidade de carga horária para agregar e incentivar maior participação discente. 0 curso de massoterapia do IFPR propôs que o aluno cumpra ao longo do curso técnico 40 horas de atividades complementares externos à instituição em que a prática massoterapêutica seja aplicada. Desse modo, o número expressivo de alunos observado no resultado desse projeto mostra que mais do que aproximar projetos de seus cursos é válida a iniciativa de vincular efetivamente as propostas com o currículo obrigatório. Assim, o projeto "Mãos Itinerantes - Massoterapia em Eventos" possui fluxo contínuo dos alunos do curso técnico em Massoterapia pois ele é, além de um projeto de extensão, uma extensão do próprio curso e portanto de capacitação profissional desses estudantes. Ao final de dois anos, cada um apresenta seu caderno de práticas conferindo então ao menos 40 horas de participação nesses eventos.

Uma vez que a prática profissional aprendida na instituição de ensino está vinculada ao contexto do mundo do trabalho que o aluno enfrentará no termino do curso facilita a compreensão de sua atividade laboral naquela comunidade e evita choques de realidades que muitas vezes são responsáveis pela desistência do novo profissional no mercado de trabalho. Conforme afirmam Souza, Torres e Dantas (2017), a práxis deve ser objeto de preocupação das 
instituições de ensino a fim de que possam garantir uma formação mais atrelada às demandas e perspectivas esperadas daquela comunidade a que o estudante pertence.

A proposta do aluno completar ao longo de sua formação a carga horária obrigatória em atividades complementares de massoterapia propicia, além dessa práxis, a possibilidade do aluno construir diferentes percepções conforme seu momento de aprendizado em determinado período do curso. Neste modelo, que corrobora com as idéias de Souza, Torres e Dantas (2017) no sentido de viabilizar a práxis no processo ensino-aprendizagem não se exige que o aluno esteja matriculado no último semestre, pois além do projeto aqui descrito há também as práticas de estágio. 0 vínculo nesse projeto de extensão promove trocas de experiências entre alunos do mesmo curso porém, em diferentes níveis uma vez que para cada evento são definidos uma média de 10 alunos com a única exigência de estarem matriculado no curso de massoterapia. A prática massoterapêutica mais utilizada no projeto é a técnica Quick Massage (massagem na cadeira) que é ministrada no primeiro semestre do curso o que facilita essa mistura de alunos ingressantes e formandos e que, por consequência, enriquece o aprendizado.

Silva e Vasconcelos (2016) ao identificarem o cenário das práticas extensionistas no âmbito dos cursos de saúde percebem que, ainda que nos últimos anos tenha-se divulgado iniciativas bem-sucedidas, a prática da extensão nesses cursos é escassa. A experiência do projeto "Mãos Itinerantes - Massoterapia em Eventos" aponta que é possível conciliar os objetivos do curso com uma proposta de extensão. Este trabalho apropria-se de uma construção coletiva junto ao colegiado de professores do curso a fim de buscar na extensão as necessidades do próprio curso como afirmam também Pezani et al. (2017) e Estácio et al. (2015). A abertura das práticas dos alunos por meio desse projeto mostrou-se positiva seja pela aderência seja pela notória expressão do aluno que sempre sinalizaram ser uma experiência motivadora. Outro fator que vale mencionar é a flexibilidade de horários que os eventos acontecem permitindo que alunos trabalhadores possam participar quando em horários alternativos, e o tempo para o cumprimento dessa carga horária ser razoavelmente tranquilo já que possibilita o prazo de aproximadamente 1 ano e meio para cumprir as 40 horas.

Por fim, no que diz respeito às práticas de extensão poderem atuar em consonância com a pesquisa o projeto em questão mostra-se inserido numa metodologia também favorável a essa prática, cumprindo com o critério da indissociabilidade entre ensino, pesquisa e extensão. Uma vez que os alunos experenciam a práxis por meio dessa iniciativa extensionista ao longo do curso, abre-se um espaço para questionamentos e novas demandas de investigação. Como exemplo, o projeto já foi tema de trabalhos de conclusão de curso e também recebeu o prêmio de melhor projeto em evento cientifico institucional. Exemplos como esse reforçam a idéia de que pesquisa e extensão não pode ser dicotomizadas mas, sim, aliadas no processo de formação do aluno. Lanzieri et al. (2011) reforçando os dizeres de Freire (1982) alertavam sobre a problemática da fragmentação dos saberes no âmbito institucional. É importante que novas iniciativas de extensão na área da saúde venham nesse contexto polivalente e que seja 
reflexa de contextos que se comunicam e se fortalecem em prol de uma educação qualificada e ajustada à realidade do universo profissional.

\section{CONCLUSÕES}

0 trabalho expõe um modelo de ação extensionista vinculado a um curso de formação técnica na área da saúde. A massoterapia exige amplo espaço curricular para a prática manual de suas variadas técnicas. Ao propor um curso de extensão atrelado às necessidades curriculares e formatado de modo a integrar-se às exigências de carga horária obrigatória (por meio da vinculação de horas de práticas em ambientes externos como requisito para o término da formação) contribui-se para aproximar o ensino conteudista com o aprendizado pela experenciação.

O trabalho traz reflexões sobre a importância de se pensar um modelo de curso de saúde que privilegie projetos de extensão integrados às perspectivas de formação discente e que seja capaz de aproximar realidades através do contato do aluno com o meio externo, onde no futuro atuará profissionalmente. Além disso, nota-se também que o incentivo às práticas de extensão pode auxiliar no processo de iniciação cientifica e atuação em pesquisa uma vez que instiga o aluno a refletir e buscar mais informações sobre suas necessidades na capacitação técnica. 0 contato com o meio externo aliado à mediação institucional no processo de formação técnica é possivelmente um campo a ser melhor explorado, principalmente no que se refere aos cursos de saúde que, por essência, atua diretamente sobre os perfis e demandas da população.

\section{REFERÊNCIAS}

SEIXAS S.I.L., CORREA T.J.S., NOGUEIRA C.S.F., ZUCHELLI M.G. Atividades de extensão no aprimoramento do processo ensino-aprendizagem na formação de alunos do projeto: "Curso de atualização: aspectos morfofuncionais e clínicos da cabeça e pescoço" na Universidade Federal Fluminense UFF. Cidadania em ação: Revista de extensão e Cultura, n. 2, v. 1, p. 1-11, 2008;

ESTACIO M.M.S., AGUIAR A.C.V.V., ROCHA B.N.G.A., SILVA F.C.B. Formação técnica em práticas integrativas e complementares em saúde na escola de saúde da UFRN. Revista Bras da Educação Profissional Tecnológica (RBEPT) n. 8, v. 1, p. 34-42, 2015;

SILVA M.S., VASCONCELOS S.D. Extensão universitária e formação profissional: avaliação da experiência das ciências biológicas na Universidade Federal de Pernambuco. Estudos em avaliação Educacional, v.17, n.33, p. 119-136, 2006;

PIERSON A.C., CORTEGOSO A.L., ARAUJO FILHO, T. Flexibilização curricular. experiências e 
perspectivas. IN: THIOLLENT M., CASTELO BRANCO A., GUIMARAES R.G., ARAUJO FILHO T. Extensão Universitária: conceitos, métodos e práticas, v. 1, p. 41-55, 2003;

FREIRE P. Extensão ou comunicação? Rio de Janeiro: Paz e Terra, 1982, 93p.

SOUZA D.D.F., TORRES M.J.F., DANTAS S.F. Percepção da relação teoria e prática no trabalho docente: um estudo com professores da área da saúde. Rev Bras Educação Profissional e Tecnológica (RBEPT) n.1, v.12, p. 125-139, 2017;

CHESANI F.H., WACHHOLZ L.B., OLIVEIRA M.A.M., SILVA C., LUZ M.E., FABRIS F.A., ENGEL B. Ensino e pesquisa: o tripé da universidade. Conexão v. 13, n.3, p.454-561, 2017;

BRASIL. Constituição (1988). Constituição da República Federativa do Brasil. Brasília, DF: Senado Federal, 1988, $292 \mathrm{p}$.

PEZZANI B.C., CIARMELLA M.L., ODEM A.B., LARRAIN R.D., MARINELARENA A.J., ANABITARTE J., MINIVIELLE M.C. Modelo de programa em controle de parasitose intestinal e nutrição em estudantes da Argentina: integração docência, extensão e investigação. ???

RESENDE J.C., ALERS R.B.S., COUTINHO M.S., BRAGAGNOLI G., ARAUJO C.R.F. Importância da iniciação científica e projetos de extensão para graduação em Medicina. Rev Bras de Ciências da Saúde, v.15, n.1, p.11-18, 2013;

LANZIERI P.G., CLARO L.B., BRAGANÇA F.C.R., MONTEZANO V.R.S., SILVA C.S. Boa noite, Bom dia HUAP! Uma experiência de humanização na formação de profissionais da área da saúde. Interface, v.15, n.36, p.289-297, 2011;

BRASIL. Ministério da saúde. Política Nacional de Humanização- Humaniza SUS. Brasilia: Ministerio da Saúde, 2004

SANTANA, CPV; NASCIMENTO, A. Práticas Integrativas e complementares: cuidado integral dentro da atenção psicossocial através de práticas corporais. Bahia. Disponível em: http:// www7.bahiana.edu.br//jspui/handle/bahiana/332 Acesso em 19 de novembro, 2017 